\title{
Effect of Monocrotophos on the mortality of Apple snails
}

\author{
N. Tripathi ${ }^{1}$, R. Pandey ${ }^{2}$ \\ ${ }^{I}$ Department of Zoology, S. K. M. University, Dumka (Jharkhand), India \\ ${ }^{2}$ Department of Zoology, S. K. M. University, Dumka (Jharkhand), India
}

\begin{abstract}
Monocrotophos is a synthetic organic compound, classified as organophosphate pesticide. It is widely used for pest control in a variety of crops except vegetables in India. It is widely sprayed in paddy fields. Exposure of Apple snails, Pila globosa the inhabitants of paddy field are a cause of concern, as they are eaten by the farm laborers and local village people. However, they are considered as hardy animals instead they are affected by the said pesticide and hence cannot be picked up for consumption after spray of pesticides. In the present investigation, Pila globosa is picked up from the pond adjacent to paddy fields. They were subjected to different concentrations of the Monodhan-36\% S. L., brand name of Monocrotophos. In 24 hours, animals show mortality at very high concentration. But with increase in exposure period they become more susceptible. Decrease in response to stimuli was observed which confirm disruption in acetyl cholinesterase activity as Monocrotophos is a well known acetyl cholinesterase inhibitor.
\end{abstract}

Keywords: Monocrotophos, Pila globosa, Monodhan-36\% S. L., mortality

\section{Introduction}

Apple snails are the most common species found in Bihar and Jharkhand. Zoologically, apple snail is Pila globosa. It is the poor man's meat in the Northern India. It flourishes well in rice paddies, ditches, pond and bank of seasonal rivers and while often considered as pests, it is eaten by farmers and pet birds.

The indiscriminate use of pesticides in paddy fields pose a threat to the existence of shelled animals as they may affect the biochemical constituent [1] resulting in abnormal changes in the behavior and physiology. In the present scenario, agriculture completely depends on chemicals. Excess use of chemicals in the form of fertilizers, pesticides, herbicides, etc. pollutes the environment. Polluted environment is not suitable for any living organisms [2]. Mollusks, especially Pila is considered as hardy animal, but being herbivores, any change in soil or water greatly affect their activity and feeding, It swiftly encloses itself in the shell and it is the primary indication of altered environment viz. temperature, $\mathrm{pH}$, hardness of soil and water, humidity or dryness of air.

Mortality is a key factor in toxicological studies. LC50, sub lethal and LC100 is the lethal dose of toxin for aquatic and amphibious animals. It is the concentration of toxin that theoretically kills $50 \%$ and $100 \%$ of the total population of the subject animals within a fixed period of time [3]; [4]; [5]. For evaluation of the extent of toxicity of a toxin, parts per million, ppm or parts per billion, ppb are generally used for concentration measurement.

The lethality of any toxin depends on many biotic and abiotic factors. Biotic factors include animal weight [6], developmental stage of test animal [7], presence of exoskeleton or chitinous covering, speed of movement of animal etc. while abiotic factors include the period of exposure, temperature [8], ph, alkalinity or acidity and dissolved oxygen contents of the medium.

In the present study, acute toxicity of rice pesticide Monocrotophos was assessed on Pila globosa. Monocrotophos was first introduced in 1965 by Ciba AG and Shell Chemical Co. USA. This pesticide is an organophosphate with broad-spectrum contact and systemic activity against insects and mites It is originally used to control sucking, chewing and boring arthropods on cotton, sugarcane, peanuts, ornamental plants, and tobacco[9].It is applied using aerial, ground-rig and directed sprays and penetrates plant tissue rapidly and has residual activity. Monocrotophos was registered for 14 crops in India by the Central Insecticides Board and Registration Committee (CIBRC). These plants are paddy, maize, Bengal gram, green gram, pea, red gram, sugar cane, cotton, castor, mustard, citrus fruits, mango, coffee and cardamom[10]. The EU has classified monocrotophos as dangerous for the environment. According to the WHO classification, it is in Ib i.e. highly hazardous. 


\section{Materials and Methods}

For the present study, freshwater, amphibious snail, Pila globosa was selected as subject animal and Monocrotophos by the brand name of Monodhan-36\% S. L. was selected as a toxicant.

\subsection{Experimental design}

Shelled fishes were collected from the pond near S. P. College, Dumka, Jharkhand and brought to the laboratory. They were kept in plastic tubs of 10 liters capacity for acclimatization. They were daily provided with fresh leaves of cabbage and lily. Ventilation was also provided for their acclimatization. Mature snails of average weight 10-13 grams and length 5-7 centimeters were selected and put in plastic tubs in 5 liters of water. Eight tubs were taken with 10 snails in each tub. One trough was considered as control and other seven for different concentrations i.e. 100 ppm, 200 ppm, 300 ppm, 400 ppm, 500 ppm, 600 ppm, 700 ppm of Monodhan$36 \%$ S. L. for different time interval of 24 hrs., 48 hrs., 72 hrs. and 96 hrs.

The mortality responses of intoxicated snails were studied by recording a number of casualties from each tub after 24, 48, 72 and 96 hours. The dead animals were removed without delay to avoid other exogenous factors taking centre stage. The experiments were repeated thrice for avoiding the error.

Percent mortality rates were recorded for different time intervals. The values above 0.5 were rounded off to next higher number while below 0.5 values were rounded off to the lower numbers. Final data were subjected to probit analysis [11]; [12] to know the $\mathrm{LC}_{50}$ after stipulated time interval.

\section{Observation}

The amphibious, freshwater mollusk, Pila globosa when exposed to different concentrations of Monodhan-36\% S. L. showed varied level of response. No mortality was observed in control experiments. 24 hours exposed snails showed mortality at higher concentrations, but they stop taking food after the application of toxicant. Mucous secretion was not observed. Treated animals stop eating in every set of experiment, but good mobility of animals was observed at lower concentrations. With the increase in exposure time and concentration of pesticide, mobility of animals diminished and then ceased. At lower concentrations of Monodhan, initially the animals enclosed itself inside the shell, but later on, they came out of their shells and showed movement. Increase in concentration and prolonged exposure arrest their movement and did not retract voluntarily inside shell. Their body was outside the shell, but absence of movement was observed and only when disturbed they respond by retracting their body. The response to stimuli decreases gradually which ultimately leads to death.

\section{Result}

The mortality percent is recorded in Table 1 . By using percent mortality data the probit(Y) was determined, concentration was converted to $\log _{10}(\mathrm{X})$. The regression equation were obtained by Microsoft office excel, 2007 and $\mathrm{LC}_{50}$ values were determined by using values of "regression coefficient, $\mathrm{b}$ and" intercept", $\mathrm{a}$. The data of regression equations of treated Pila for 24 hours, 48 hours, 72 hours and 96 hours are shown in Table 2. The graphs of Probit $(\mathrm{Y})$ against $\log _{10}$ concentration $\left(\log _{10} \mathrm{X}\right)$ were plotted for different concentrations [13] and from these graphs $\mathrm{LC}_{50}$ values were estimated by using Probit as five.

Calculated value of $\mathrm{LC}_{50}$ for Monodhan-36\% S. L. were found to be $1265.1 \mathrm{ppm}$ for 24 hours of exposure, $743.07 \mathrm{ppm}$ for 48 hours of exposure, $486.43 \mathrm{ppm}$ for 72 hours of exposure, $439.55 \mathrm{ppm}$ for 96 hours of exposure. By graph the $\mathrm{LC}_{50}$ values were found to be $1264 \mathrm{ppm}$. for 24 hours of exposure, $745 \mathrm{ppm}$ for 48 hours of exposure, $484 \mathrm{ppm}$ for 72 hours of exposure, $440 \mathrm{ppm}$ for 96 hours of exposure. The value determined by both calculations and graphical methods slightly varied.

From the data, it was clear that the percent mortality increased with increase in concentration and exposure period [14]. Hence, indiscriminate use of high dose of monocrotophos should be completely avoided if people eat snails of that field.

\section{Discussion}

The gastropods are the common indicators of pollution level because they are more or less sedentary for easy and repeated experiment and observation. They also tolerate high level of contaminants [15]; [16].

The observations support the earlier work done by [17] in Paratox exposed freshwater snail, Cerastus moussonianus. Work on effect of mercury chloride in fresh water gastropod Indoplanorbis exustus by [18] support the present work. This result is in agreement with the result of [19] when Thiara lineata were exposed to various pesticides like Organochlorine (Endosulfan), Organophosphate, Monocrotophos (Nuvacran), Synthetic Pyrethroid (Cymbush) and Carbamate (Sevin).

It is a well known fact that monocrotophos is an acetyl cholinesterase inhibitor [20]. Decrease response to stimuli and loss of retraction power indicates neurosecretory malfunctioning at the neuromuscular junction and in the nervous system. This may be one of the causes of mortality along with cessation of feeding. 


\section{Conclusion}

Mortality due to use of Monocrotophos of Pila globosa is proportional to the concentration and time of exposure of Monocrotophos, so people should completely avoid picking apple snails for consumption after its spray. For eating purpose mollusks should be reared separately in ponds or ditches. If people eat apple snails from the paddy field they should ensure that snails are healthy and do not show any sign of intoxication like delayed response to stimuli, moribund condition, loose operculum, etc.

Table 1: Mortality response of freshwater snail, pila globosa to Monodhan $36 \%$ S. L., trade name of Monocrotophos

\begin{tabular}{|l|l|l|l|l|}
\hline \multicolumn{5}{|c|}{ Percent mortality for freshwater snail, Pila globosa when exposed to Monodhan-36\% S. L. } \\
\hline Concentration in ppm & 24 hrs. & 48 hrs. & 72 hrs. & 96 hrs. \\
\hline Control & 0 & 0 & 0 & 0 \\
\hline 100 & 0 & 0 & 0 & 0 \\
\hline 200 & 0 & 0 & 0 & 17 \\
\hline 300 & 0 & 0 & 20 & 0 \\
\hline 400 & 0 & 0 & 37 & 20 \\
\hline 500 & 0 & 13 & 73 & 23 \\
\hline 600 & 10 & 27 & 90 & 47 \\
\hline 700 & 13 & 43 & 93 \\
\hline
\end{tabular}

Table 2: Numerical data of regression coefficient " $b$ " and intercept " $a$ " for the calculation of $\mathrm{LC}_{50} \mathrm{value}$ and regression equations for determination of Monodhan 36\% S. L. toxicity

\begin{tabular}{|l|l|l|l|}
\hline Time of exposure in hrs. & b & \multicolumn{1}{|c|}{ a } & Regression equation \\
\hline 24 & 1.025 & 1.82 & $1.025 \mathrm{X}+1.82$ \\
\hline 48 & 6.509 & -13.69 & $6.509 \mathrm{X}-13.69$ \\
\hline 72 & 6.192 & -11.64 & $6.192 \mathrm{X}-11.64$ \\
\hline 96 & 8.012 & -16.18 & $8.012 \mathrm{X}-16.18$ \\
\hline
\end{tabular}

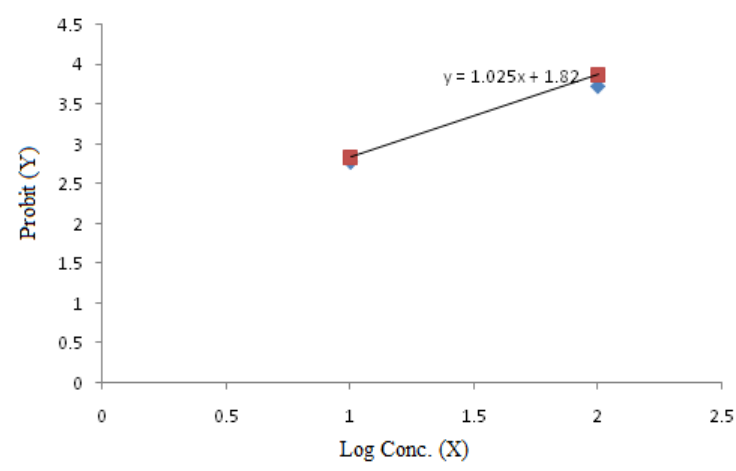

Graph 1. LC50 value and regression equation of Monodhan-36\% S. L. for amphibious, freshwater snail, Pila globosa at $24 \mathrm{hrs}$. of exposure.

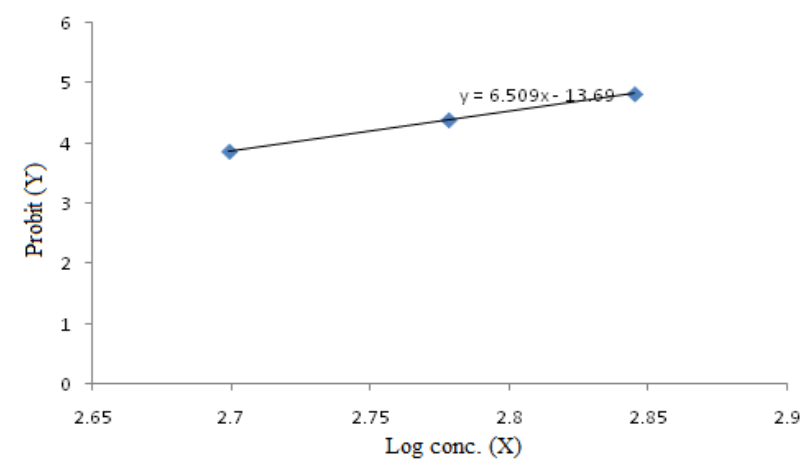

Graph 2. LC50 value and regression equation of Monodhan-36\% S. L. for amphibious, freshwater snail, Pila globosa at $48 \mathrm{hrs}$. of exposure. 


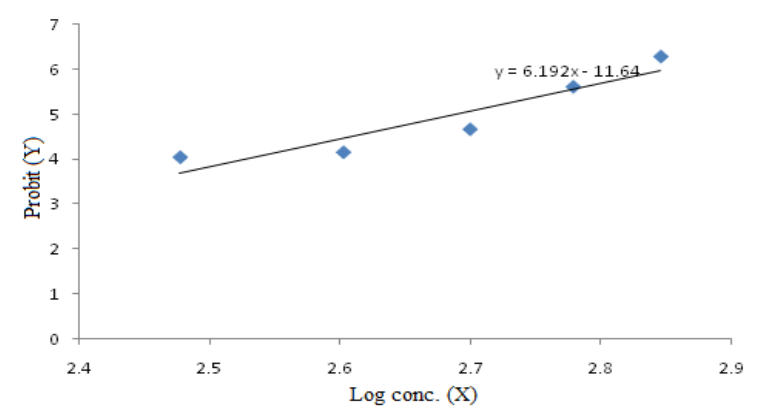

Graph 3. LC50 value and regression equation of Monodhan-36\% S. L. for amphibious, freshwater snail, Pila globosa at $72 \mathrm{hrs}$. of exposure

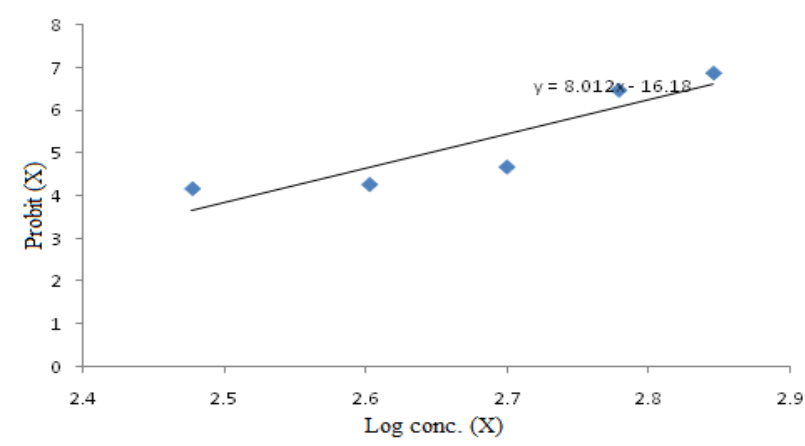

Graph 4. LC50 value and regression equation of Monodhan-36\% S. L. for amphibious, freshwater snail, Pila globosa at $96 \mathrm{hrs.} \mathrm{of} \mathrm{exposure.}$

\section{Acknowledgement}

Authors are thankful to Prof. Akhileshwar Prasad, Former Head, Department of Statistics, Patna University for helping in statistical analysis and the authorities of S. K. M. University, Dumka, Jharkhand for providing necessary research facilities.

\section{References}

[1] J.T. Jagtap, K.B. Shejule and S.B. Ubarhande. Acute effect of TBTCL on protein alteration in freshwater bivalve, Lamellidens marginalis, International Multidisciplinary Research Journal 1(8), 2011 13-16

[2] Menzel, D.W.. Summary of experimental results controlled ecosystem pollution experiment. Bull. Mar. Sci. 27, 1977, 142-145.

[3] Buikema, A.L. and Benfield, E.F.. Effect of pollutant on freshwater invertebrates. J. Water. Pollu. Cont. Fed. 54, 1982, 862-868.

[4] Sivaramakrishna, B., Surehs, A. and Radhakrishnaiah, K.. Assessment of mercury toxicity by the changes in oxygen consumption and ion levels in the freshwater snail, P. globosa and the mussel Lamellidens marginalis. Bull. Environ. Contam. Toxicol. 46, 1991, 913-920

[5] Schmitt, C.J., Zajicek, J.L., May, T.W. and Courmum, D.F. Organochlorine residues and elemental contaminants in U. S. Freshwater fish. National contaminants Biomonitoring Programme. Review of Environmental Contamination Toxicology, 162, 1999, 43-102.

[6] Pickering, Q.H., Handerson, S. and Lemle, A.K. The toxicity of organic phosphorus insecticide to different species of warm water fishes. Trans. Amer. Fish. Sco. 91, 1962, 175-184

[7] Kamaldeep, K.H. and Toor, S. Toxicity of pesticides to embryonic stage of Cyprinus carpio. Ind. Exp. Biol. 15, 1975, 193-196.

[8] Macek, K.J., Hutchinson, C and Cope, O.B. The effect of temperature on the susceptibility of blue gills of rainbow trout to selected pesticides. Bull. Environ. Conta. Toxicol. 4, 1969, 174

[9] ACGIH (American Conference of Governmental Industrial Hygienists). 2002. Monocrotophos. Documentation of the Threshold Limit Values and Biological Exposure Indices. Suppl. to the $7^{\text {th }}$ edition. ACGIH, Cincinnati, OH.

[10] State of Pesticide Regulations in India, Centre for Science and Environment, New Delhi, 2013

[11] Finney, D.J. Probit analysis, (Third Edition, Cambridge University Press, New York. 318, 1971)

[12] Hahn, E. D. and R. Soyer. "Probit and Logit Models: Differences in a Multivariate Realm." Retrieved May 28, 2008, from http://home.gwu.edu/ soyer/mvlh.pdf

[13] Ghosh A, Konar SK. Effects of phosphamidon on the activity of digestive enzyme in Clarius batrachus. Journal of Inland Fishery Society $5,1973,129-131$

[14] Deshmane Jini and Nanaware S. G. The Effects of Plants Toxin from Fruit Extract of Sapindus laurifolius on Mortality of Fresh Water Snail, Bellamya bengalensis (Lamark). Biological Forum-An international journal, 3(2), 2011, 48-51.

[15] Forester, A.J.: Monitoring the bioavailability of toxic metals in acid - stressed lakes using pelecypod molluscs clams and mussels. Proc.

Univer of Montana annual Conf. Trace substance environ. Hlth, 14, 1980, 142-147

[16] Havlik, M.F. and L.L. Marking: Effect of contaminants on mollusks (Unionidae). A review U.S dept, of Interior fish and wildlife service Resource Publications. 1987, 164. 
[17] Magare SR and Kulkarni AB. Effect of paradox on the brain neurosecretory profile of the snail Cerastus moussonianus, Bull. Ass. Zool., 2(1), 1995, 47-51.

[18] Patil HZ and Mahale PN. Toxicity effect of mercury chloride on the freshwater Gastropod, Indoplanorbis exustus, Journal of Ecobiotechnology, Vol-2/8, 2010, 21-24.

[19] Ahirrao KD, Kedkar GD. Variations in LC50 of some pesticides due to physico-chemical parameters and impact of sevin on neurosecretory cells of a fresh water snail, Thiara lineate, Journal of Research in Biology (2012) 1, 2012, 050-056

[20] Health Council of the Netherlands: Committee on Updating of Occupational Exposure Limits. Monocrotophos; Health-based Reassessment of Administrative Occupational Exposure Limits. The Hague: Health Council of the Netherlands, 2003; 2000/15OSH/073 